\title{
Improved water saturation estimation in shaly sandstone through variable cementation factor
}

\author{
Wan Zairani Wan Bakar ${ }^{1}$ (D) Ismail Mohd Saaid ${ }^{2} \cdot$ Mohd Riduan Ahmad $^{3} \cdot$ Zulhelmi Amir $^{4} \cdot$ Nur Shuhadah Japperi $^{1}$. \\ Mohd Fazril Irfan Ahmad Fuad ${ }^{1}$
}

Received: 12 July 2021 / Accepted: 16 November 2021 / Published online: 1 December 2021

(c) The Author(s) 2021

\begin{abstract}
Estimation of water saturation, $S_{w}$, in shaly sandstone is an intricate process. The surface conduction of clay minerals adds up to the electrolyte conduction in the pore spaces, thus generating high formation conductivity that overshadows the hydrocarbon effect. In each resistivity-based water saturation model, the key parameter is formation factor, $F$, which is typically derived from Archie's Law. Referring to a log-log plot between formation factor and porosity, cementation factor reflects the slope of the straight line abiding Archie's Law. In the case of shaly sandstone, derivation based on Archie's Law in combination with Waxman-Smits equation leads to higher cementation factor, $m^{*}$. In the shaly parts of the reservoir, high $m^{*}$ is counterbalanced by clay conductivity. Nonetheless, high $m^{*}$ used in clean parts increases $S_{w}$ estimation. In this study, the variable cementation factor equation is introduced into the standard correlation of $S_{w}$ versus Resistivity Index, $R I$, to develop a water saturation model with shaly sandstone parameters. Data retrieved from two fields that yielded mean arctangent absolute percentage error (MAAPE) were analysed to determine the difference between calculated and measured data within the 0.01-0.15 range for variable cementation factor method. The conventional method yielded maximum MAAPE at 0.46.
\end{abstract}

Keywords Shaly sandstone $\cdot$ Formation factor $\cdot$ Variable cementation factor $\cdot$ Water saturation

\section{Introduction}

Water saturation, $S_{w}$, refers to crucial petrophysical information for volumetric estimation. This parameter can be determined from the formation resistivity in combination with porosity and several other constants. The most common method used to estimate $S_{w}$ is by using Archie's model described in the equation given below:

Wan Zairani Wan Bakar

zairani@uitm.edu.my

1 School of Chemical Engineering, College of Engineering, Universiti Teknologi MARA, Shah Alam, Malaysia

2 Department of Petroleum Engineering, Faculty of Geosciences and Petroleum Engineering, Universiti Teknologi PETRONAS, Seri Iskandar, Malaysia

3 Polygon Scientific Sdn Bhd, Puncak Alam, Malaysia

4 Department of Chemical Engineering, Faculty of Engineering, University of Malaya, Kuala Lumpur, Malaysia
$S_{w}{ }^{n}=\frac{F R_{w}}{R_{t}}$

where $R_{w}=$ formation fluid resistivity (ohm m), $R_{t}=$ true formation resistivity (ohm.m), $n=$ saturation exponent, $m=$ porosity exponent or cementation factor.

According to Archie (1942), the equation was established based on several prior studies, including Martin et al. (1938), Jakosky and Hopper (1937), Wyckoff and Botset (1936), and Leverett (1941). Archie expanded the equation by embedding quantity $F$, also known as the formation resistivity factor or simply referred as formation factor. This quantity denotes the resistivity ratio of fully water-saturated rock, $R_{o}$, to the formation fluid resistivity, $R_{w}$. In terms of conductivity, it signifies the ratio of formation fluid conductivity, $C_{w}$, to the conductivity of fully water-saturated rock, $C_{o}$ (see Eq. 2).

$F=\frac{R_{o}}{R_{w}}=\frac{C_{w}}{C_{o}}$

Archie prescribed that the formation factor, $F$, is always constant for a given rock since $R_{o}$ increases linearly with

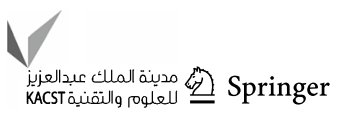


increment in $R_{w}$. Hence, $F$ is a function of rock type and characteristics (Archie 1942). However, the following studies found that the formation factor is not constant, especially for sample with high clay content saturated in low brine conductivity (Patnode and Wyllie 1952; Winsauer and McCardell 1953; Wyllie and Southwick 1954; Sauer et al. 1955). More studies depicted that the conductance behaviour in samples with high clay content differed from that in clean samples (Waxman and Smits 1968; Clavier et al. 1984). The conductance pattern on a $C_{o}$ versus $C_{w}$ plot can be divided into two regions; nonlinear and linear (see Fig. 1). In the nonlinear zone, the formation factor, inverse of the graph slope, is not constant until a point where sufficiently high $C_{w}$ is reached. The formation factor becomes constant after this point as $C_{w}$ displays further increment.

The linear region is manageable since the formation factor is constant and its log-log plot against porosity can result in straight law based on Archie's law. However, for nonlinear region, it is questionable if the plot still conforms to Archie's law since the formation factor is not constant. The nonlinear zone indicates the significant impact of clay conductivity on total conductivity. This has been the basis for the parallel resistors theory (Patnode and Wyllie 1952; Clavier et al. 1984) that defines resistivity from clay surface and resistivity from electrolyte in pore spaces as two resistors connected in parallel.

Based on numerous shaly sandstone conductivity model initiated during the early years, clay conductivity was introduced as an additional parameter; $X$ to the bulk conductivity, as expressed in Eq. 3 (Worthington 1985). This shows that the formation factor is a constant of proportionality for the relationship between $C_{o}$ and $C_{w}$ with $\mathrm{X}$ as the intercept on $\mathrm{y}$-axis.

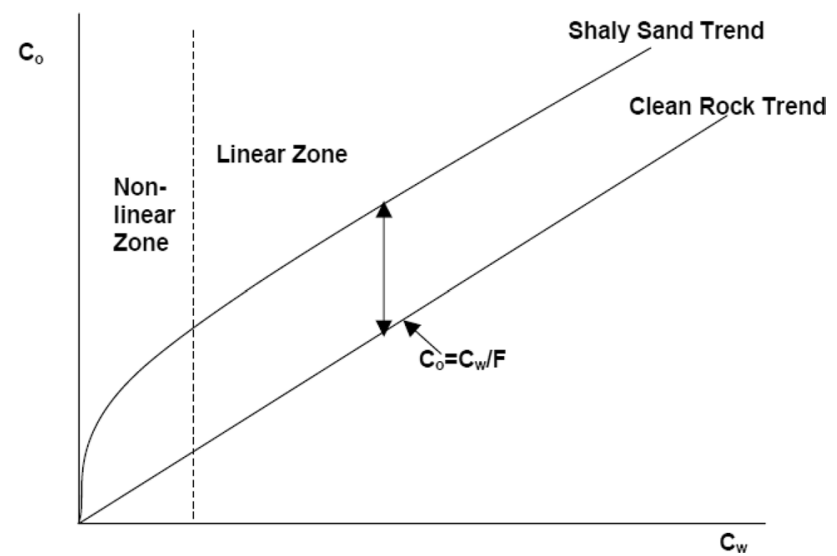

Fig. 1 Typical conductivity $C_{o}-C_{w}$ plot for shaly sandstone. Source: Worthington (1985)
$C_{o}=\frac{C_{w}}{F}+X$

Equation 3 solves for the formation factor in linear region (high conductivity region) from the slope of the plot and the value of clay conductivity is represented by $X$. The bulk conductivity is shifted by the amount of $X$ determined from the ordinate intercept. Since the formation factor can be derived from the slope of linear line, this approach technically solves for the intrinsic value rather than formation factor for shaly sandstone, which is also known as a non-constant. For $S_{w}$ estimation in shaly sandstone, the efficacy of this formation factor when embedded into the equation is still unclear because the intrinsic formation factor is meant for clean sandstone only. In most complex heterogeneous lithology, the formation factor varies even within the same reservoir.

\section{Water saturation from variable cementation factor}

Bakar et al. (2019) proposed an improved equation to model the formation factor by varying the cementation factor with clay conductivity and porosity. Clay conductivity is defined as cations mobility, $B$, multiplied by effective clay concentration, $Q_{v}$.

$F^{*}=\frac{1}{\phi^{\frac{\log _{10}\left(1+B Q_{V} R_{W}\right)}{\log _{10} \phi}+m}}$

Referring to Eq. 4, the exponent of porosity $\left(\frac{\log _{10}\left(1+B Q_{V} R_{w}\right)}{\log _{10} \phi}+m\right)$ is the cementation factor for shaly sandstone, $m^{*}$. The value varies with both clay conductivity and porosity, which enables $F^{*}$ to change accordingly.

Resistivity Index, $R I$, measurement is the basis for the derivation of $S_{w}$ equation. It is defined as the ratio of true core plug resistivity, $R_{t}$, to fully water-saturated core plug resistivity, $R_{o}$. The general relationship between $R I$ and $S_{w}$ is expressed in Eq. 5. This equation is valid for any type of formation as long as it is water-wet (Mungan and Moore 1968).

$R I=\frac{1}{S_{w}{ }^{n}}$

The parameters in $R I$ for shaly sandstone are represented by asterisks, as given below:

$R I^{*}=\frac{1}{S_{w}{ }^{*}}$

All asterisk parameters represent measurement in shaly sandstone. For shaly sandstone, RI is as follows: 
$R I^{*}=\frac{R_{t}^{*}}{R_{o}^{*}}=\frac{C_{o}{ }^{*}}{C_{t}^{*}}$

Hence, the total conductivity of shaly sandstone in terms of $S_{w}$ is expressed as follows:

$\frac{C_{t}^{*}}{C_{o}{ }^{*}}=S_{w}^{n^{*}}$

This equation can be applied to predict if the measured conductivity, $C_{t}^{*}$, is proportional to the percentage of water in the pore spaces. This is because the medium for electrical current flow is mainly through electrolyte. Next, $C_{t} *$ is reduced from the initial value of $C_{o}{ }^{*}$, along with reduction in water portion in pore spaces. The impact of reduction in electrical current path is on both electrolyte and clay surface conduction. Equation 8 is rearranged and the bulk conductivity of shaly sandstone is expanded into its terms in $B Q_{v}$ to yield the following:

$S_{w}^{n^{*}}=\frac{C_{t}^{*}}{C_{o}^{*}}=\frac{C_{t}^{*}}{\frac{1}{F}\left(C_{w}+B Q_{v}\right)}$

Conversion of $C_{w}$ to $R_{w}$ :

$S_{w}{ }^{n^{*}}=\frac{C_{t}{ }^{*}}{\frac{1}{F R_{w}}\left(1+B Q_{v} R_{w}\right)}$

$S_{w}^{n^{*}}=\frac{F R_{w} C_{t}^{*}}{\left(1+B Q_{v} R_{w}\right)}$

$C_{t} *$ in terms of $R_{t}^{*}$ :

$S_{w}{ }^{*}=\frac{F R_{w}}{R_{t}^{*}\left(1+B Q_{v} R_{w}\right)}$

Formation factor of shaly sandstone is given as follows:

$F^{*}=\frac{F}{\left(1+B Q_{v} R_{w}\right)}$

Equation 13 is simplified to:

$S_{w}^{n^{*}}=\frac{F^{*} R_{w}}{R_{t}^{*}}$

Equation 14 denotes Archie's $S_{w}$ equation. All parameters in this equation must be properly defined to only reflect the shaly sandstone vicinity. Hence, the formation factor, $F^{*}$, in Eq. 14 is substituted by Eq. 4, which demands information pertaining to intrinsic cementation factor, $m$.

In conventional approach, the intrinsic cementation factor, $m$, is determined from the slope of bi-logarithmic plot of formation factor versus porosity, which is in accordance to Archie's Law:
$F=\frac{1}{\phi^{m}}$

This technique leaves cementation factor constant for the entire zone represented by the respective core samples. The shaly sandstone cementation factor, $m^{*}$, is estimated based on the slope of bi-logarithmic plot of shaly sandstone formation factor, $F^{*}$, versus porosity. $F^{*}$ is calculated using Waxman-Smits equation (Waxman and Smits 1968); $F^{*}=F\left(1+B Q_{v} R_{w}\right)$, which leads to $m^{*}>m$. The shortcoming of this technique can be observed in heterogeneous reservoir. This is particularly in less shaly zone, in which higher $m^{*}$ derived from this technique leads to overestimation of $S_{w}$.

Turning to this present study, its aim is to validate the feasibility of Eq. 14 in estimating $S_{w}$. The estimated $S_{w}$ from Eq. 14 was later compared with measured $S_{w}$ in $R I$ laboratory analysis because in $R I$ analysis, $R_{t}$ measurement is directly related to measured $S_{w}$. Prior to $S_{w}$ estimation, formation factor, $F^{*}$, determined from Eq. 4, was analysed because $F^{*}$ is an important parameter in Eq. 14. If Eq. 14 can estimate $S_{w}$ close to the measured value, the equation is feasible for log interpretation after identifying $B Q_{v}$. In this study, the accuracy of Eq. 14 in estimating $S_{w}$ was compared with the conventional method that used constant $m$.

\section{Core data and $S_{w}$ estimation techniques}

Two sets of RI data obtained from Sabah Basin with arbitrary name Fields A and B were deployed in this study to analyse $F^{*}$ and $S_{w}$.

\section{Field A: $\mathrm{m} *$ from conventional method}

The core samples from Field A had high porosity that ranged at $40-45 \%$. The cation exchange capacity (CEC) ranged from 1.74 to $14.42 \mathrm{meq} / 100 \mathrm{~g}$ with corresponding $Q_{v}$ of $0.07-0.49 \mathrm{meq} / \mathrm{ml}$. The conventional method using Waxman-Smits equation for $m^{*}$ determination resulted in the value of 2.30 with corresponding $m$ at 1.94 (see Fig. 2). In this method, the linear line was forced to 1.00 point following Archie's Law (see Eq. 15). Both $m$ and $m^{*}$ are the porosity exponent of the respective derived correlations. Notably, $m$ was derived from the equation of $F$ versus porosity, $\phi$, while $m^{*}$ was retrieved from $F^{*}$ versus $\phi$; whereby $F^{*}=F\left(1+B Q_{v} R_{w}\right)$.

\section{Field B: $\mathbf{m}^{*}$ from conventional method}

The core samples from Field B were composed of silty to fine grained, poor to moderately cemented sandstone. The CEC value ranged from 1.28 to $11.41 \mathrm{meq} / 100 \mathrm{~g}$ with 


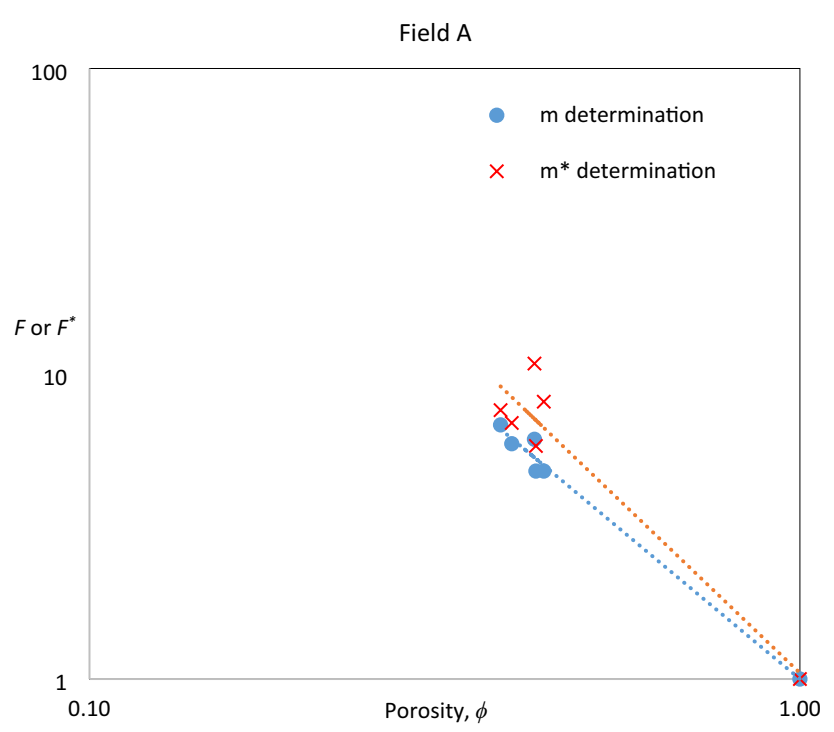

Fig. 2 Determination of $m$ and $m^{*}$ using conventional method for Field A

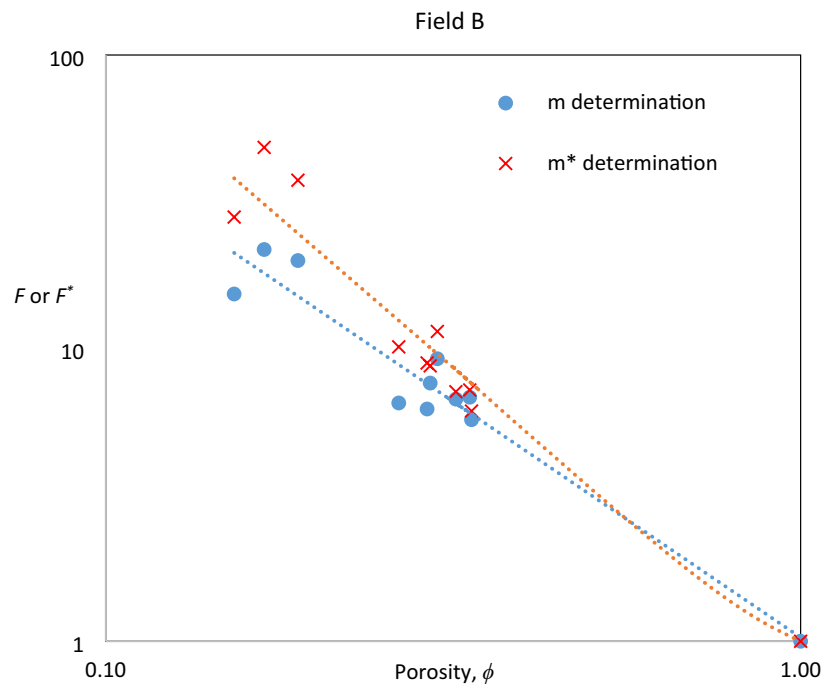

Fig. 3 Determination of $m$ and $m^{*}$ using conventional method for Field B

corresponding $Q_{v}$ of $0.07-1.51 \mathrm{meq} / \mathrm{ml}$. The conventional method using Waxman-Smits equation for $m *$ determination resulted in the value of 1.86 with corresponding $m$ of 1.64 (see Fig. 3).

Using the conventional method, $m$ was determined first from the slope of linear regression of laboratory-measured formation factor, $F$, plotted against porosity. The shaly sandstone cementation factor, $m^{*}$, which was obtained from the linear regression of $F^{*}$ (calculated from $F$ multiplied by $\left.\left(1+B Q_{v} R_{w}\right)\right)$, generated a higher value than $m$. This result contravenes the Waxman and Smits theory on excess clay conductivity, which depicts that the cementation factor is always lower in the condition that the clay conductivity is significant. Besides, the conventional approach did not justify the deviation from Archie's straight line observed in most laboratory and well log data. Due to the higher calculated $F^{*}$ value, the conventional approach assumes that bulk conductivity, $R_{o}$, is higher in shaly sandstone. This is an unjustifiable assumption since excess clay conductivity reduces $R_{o}$.

\section{Variable cementation factor for Fields A and B}

In the proposed variable cementation factor method, $m$ was estimated based on the fitting technique since a single value of $R_{w}$ was used to measure formation factor in the laboratory. The fitting technique yielded some intrinsic cementation factors with $m$ for varied sand units (see Table 1). As $m$ depended on rock characteristics, Archie (1942) proposed that $m$ ranging at 1.3-2.0 denotes loosely or partly consolidated sandstones. Additionally, $m$ also depends on grain shape (Atkins and Smith 1961; Salem and Chilingarian 1999), cementation (Wyllie and Gregory 2012; Perez 1982), lithology and mineral compositions (Ehrlich et al. 1991), tortuosity, and pore geometry (Winsauer et al. 1952; Ehrlich et al. 1991; Aguilera 1976; Owen 1952). The value of cementation exponent $m$ increases as the degree of connectedness of the pore network diminishes, all while relying on rock characteristics. The values of $m$ (Table 1) were substituted into Eq. 4 to calculate shaly sandstone formation factor, $F^{*}$. Equation 14 was used to calculate $S_{w}$ for each resistivity point of $R I$ data.

\section{Analysis and validation}

\section{Variable Formation Factor, $F^{*}$, from variable cementation factor}

Equation 4 proposed by Bakar et al. presents a new approach to estimate formation factor, $F^{*}$, in shaly sandstone. In this approach, $F^{*}$ is not the total geometric factor (as true formation factor should be), but it is the relative changes of bulk formation conductivity with respect to changes in saturating brine conductivity. This equation allows $F^{*}$ to change with clay content. Hence, its value is a variable that corresponds to both clay effect and porosity; not limited to porosity as in the conventional method. This explains the changes of formation factor in nonlinear region of the conductivity curve.

The formation factor, $F^{*}$, estimated with Eq. 4 gave good approximation to the laboratory-measured $F^{*}$ for data from Fields A and B. This is shown in the plot of $F^{*}$ calculated with Eq. 4 versus laboratory-measured $F^{*}$, which fell around the unity constant of proportionality line (see Figs. 4 and 5). The MAAPE values were 0.06 and 0.05 for Fields A and B 
Table 1 Estimated cementation factor, $m$, for each sand unit of Fields A and B

\begin{tabular}{|c|c|c|c|c|}
\hline Data & Sample number & Porosity & $Q_{v}\left(\mathrm{meq} / \mathrm{cm}^{3}\right)$ & $\begin{array}{l}\text { Estimated } \\
\text { cementation } \\
\text { factor, } m\end{array}$ \\
\hline \multicolumn{5}{|l|}{ Field A } \\
\hline \multicolumn{5}{|c|}{ Field A in Sabah Basin } \\
\hline \multirow[t]{3}{*}{ Sand Unit 1} & Sample 1 & 0.379 & 0.07 & 2.10 \\
\hline & Sample 2 & 0.393 & 0.11 & \\
\hline & Sample 3 & 0.425 & 0.13 & \\
\hline \multirow[t]{2}{*}{ Sand Unit 2} & Sample 4 & 0.423 & 0.49 & 2.50 \\
\hline & Sample 5 & 0.436 & 0.43 & \\
\hline \multicolumn{5}{|l|}{ Field B } \\
\hline \multicolumn{5}{|c|}{ Field B in Sabah Basin } \\
\hline \multirow[t]{2}{*}{ Sand Unit 1} & Sample 1 & 0.33 & 0.07 & 1.80 \\
\hline & Sample 2 & 0.30 & 0.28 & \\
\hline \multirow[t]{6}{*}{ Sand Unit 2} & Sample 3 & 0.34 & 0.08 & 1.75 \\
\hline & Sample 4 & 0.26 & 0.65 & \\
\hline & Sample 5 & 0.29 & 0.51 & \\
\hline & Sample 6 & 0.32 & 0.07 & \\
\hline & Sample 7 & 0.29 & 0.17 & \\
\hline & Sample 8 & 0.15 & 0.98 & \\
\hline \multirow[t]{2}{*}{ Sand Unit 3} & Sample 9 & 0.17 & 1.45 & 2.20 \\
\hline & Sample 10 & 0.19 & 1.04 & \\
\hline
\end{tabular}

Field A

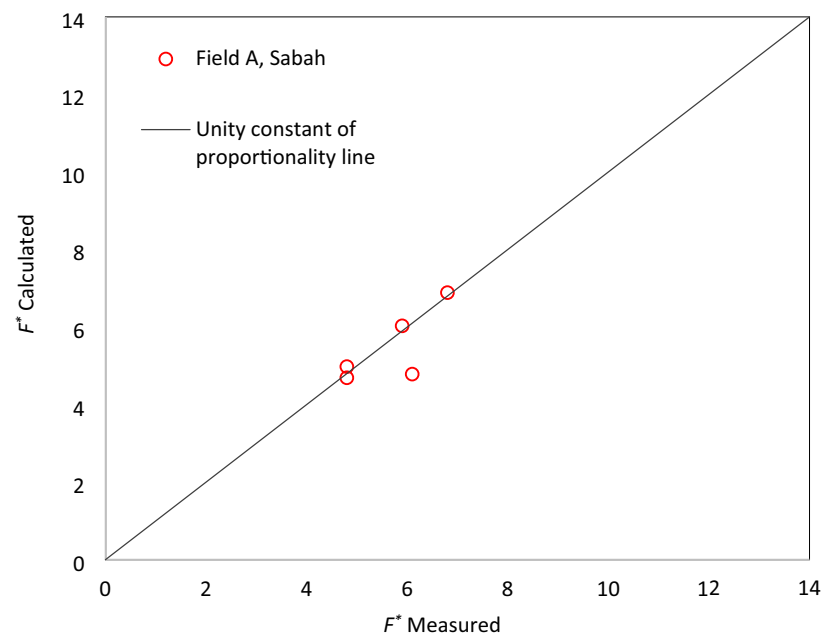

Fig. 4 Calculated $F^{*}$ versus measured $F^{*}$ for data from Field A

data points, respectively (see Table 2). The MAAPE was calculated using Eqs. 16 and 17, as prescribed by Kim and Kim (2016).

$M A A P E=\frac{1}{N} \sum_{t=1}^{N} A A P E_{t}$ fort $=1, \ldots N$

where

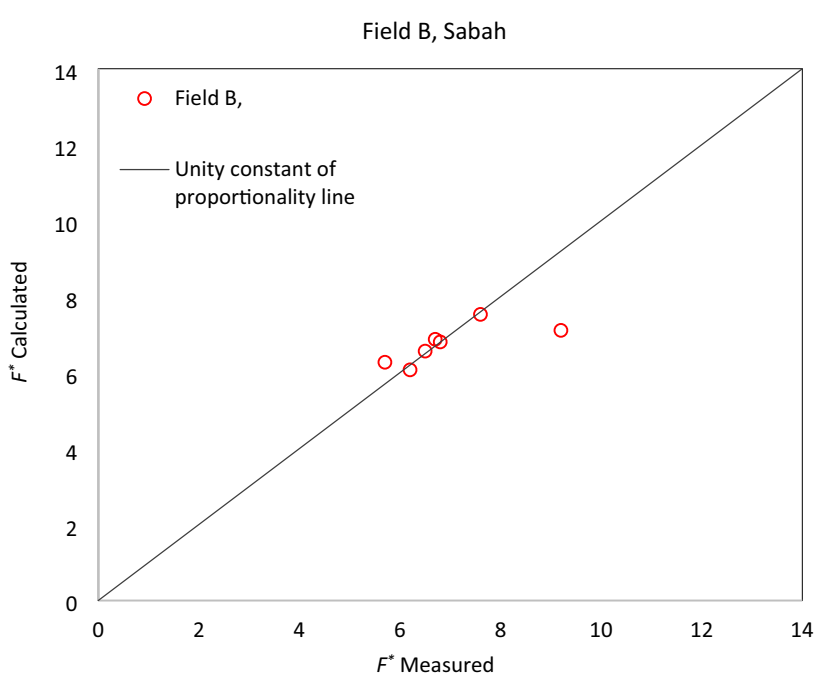

Fig. 5 Calculated $F^{*}$ versus measured $F^{*}$ for data from Field B

$A A P E_{t}=\arctan \left(\left|\frac{\text { measured value }- \text { calculate value }}{\text { measured value }}\right|\right)$

Large errors were noted in some samples. For example, Samples 4 and 2 of Fields A and B had AAPE values of 0.21 and 0.22 , respectively. This is ascribed to inaccurate prediction of $m$ values as input to Eq. 4. Sample 4 was predicted to share a similar sand unit as Sample 5, which 
Table 2 Mean arctangent absolute percentage error (MAAPE) for Fields A and B data points

\begin{tabular}{lccc}
\hline Sample number & Calculated $F^{*}$ & Measured $F^{*}$ & AAPE \\
\hline Field A, Sabah & & & \\
Sample 1 & 6.89 & 6.80 & 0.01 \\
Sample 2 & 6.03 & 5.90 & 0.02 \\
Sample 3 & 4.98 & 4.80 & 0.04 \\
Sample 4 & 4.79 & 6.10 & 0.21 \\
Sample 5 & 4.69 & 4.80 & 0.02 \\
MAAPE & & & 0.06 \\
Field B, Sabah & & & \\
Sample 1 & 6.81 & 6.80 & 0.00 \\
Sample 2 & 7.11 & 9.20 & 0.22 \\
Sample 3 & 6.27 & 5.70 & 0.10 \\
Sample 4 & 6.57 & 6.50 & 0.01 \\
Sample 5 & 6.07 & 6.20 & 0.02 \\
Sample 6 & 6.88 & 6.70 & 0.03 \\
Sample 7 & 7.53 & 7.60 & 0.01 \\
Sample 8 & 14.59 & 15.30 & 0.05 \\
Sample 9 & 21.92 & 21.70 & 0.01 \\
Sample 10 & 20.75 & 19.90 & 0.04 \\
MAAPE & & & 0.05 \\
\hline
\end{tabular}

scored $m=2.50$. This prediction was inaccurate as the samples might not derive from the same sand unit. In this present study, sand unit was predicted based on the depth from where the samples were taken and the porosity of the samples. However, only the two mentioned samples in the sand unit caused some difficulty in determining the most accurate m. A similar case was observed for Sample 2 of Field B, which displayed a similar sand unit with only Sample 1.

\section{$S_{w}$ from conventional and variable $m^{*}$ methods}

Typically, the conventional method employs established shaly sandstone water saturation models, which are manipulated from the inverse power law correlation between $S_{w}$ and $R I$. In the established shaly sandstone water saturation models, the formation factor via Archie's Law is applied. The inverse power law relationship of $S_{w}-R I$ signifies that the electrical current flow is dependent on brine geometry (Herrick and Kennedy 2009). The abrupt increase of $C_{t}{ }^{*}$ in low water saturation regime is attributed to the percolation theory by Ghanbarian et al. (2014); depicting that abrupt increment in relative tortuosity is related to reduction in water content. The relative tortuosity gradually increases from fully saturated to near the threshold water content and diverges as the water content approaches its irreducible values. In fact, tortuosity has better definition in terms of connectivity and connectedness of electrical current paths (Glover, 2009). Cai et al. (2019) reported that fluid flow and

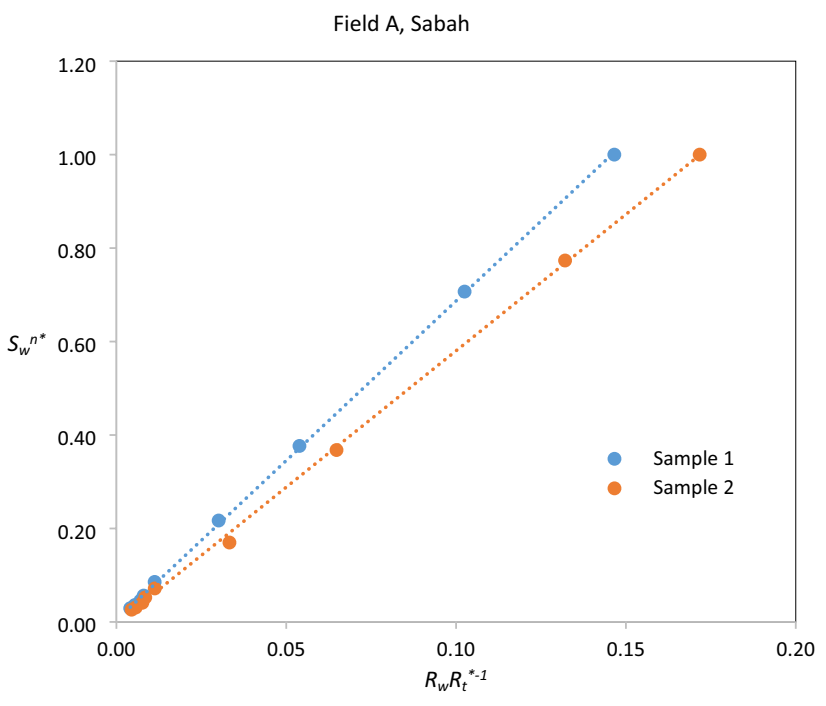

Fig. $6 S w^{n *}$ plotted against $R_{w} R_{t}^{*-1}$ for Samples 1 and 2 of Field A (straight line denotes linear relationship)

electrical conduction display similar behaviour. The validity of this assumption is supported by the notion that free electrolyte and clay surface conduction have the same path.

In Eq. 14 , all parameters, i.e. $n^{*}, F^{*}$, and $R_{t}^{*}$, represent shaly condition. It is predicted that when water saturation reduces, $S_{w}$ will reduce electrical conduction through free electrolytes and clay surface cations. Note that our assumption on clay surface conductance differs from that proposed by Waxman and Smits—clay surface conductance or $B Q_{v}$ increases with reduction in $S_{w}$. Therefore, clay surface conduction becomes higher as $S_{w}$ approaches zero. Nonetheless, the saturation exponent, $n$ * (represents changes in $R_{t}^{*}$ with respect to changes in water portion), depends on the decreasing connectivity and connectedness of the electrical current path, which has either direct or indirect link with the geometric factor of the rock.

Since the generic term $R I$ refers to changes in measured resistivity, $R_{t}$, relative to fully water-saturated resistivity, $R_{o}$; in which $R_{o}$ is fixed, the power law describes $R_{t}$ profile with changes in $S_{w}$. In shaly sandstone, the correlation can be deployed in well log interpretation as long as $R_{o}{ }^{*}$ is identified. With respect to laboratory measurement, $F^{*}$ is not a total geometric factor, but instead, a ratio of measured resistivity of fully water-saturated shaly, $R_{o}{ }^{*}$, to saturating water resistivity, $R_{w}$. Thus, $R_{o}{ }^{*}$ can be determined from $F^{*} R_{w}$; with $F^{*}$ defined by Eq. 4 .

Referring to Eq. 14, the measured $S w^{n *}$ has a linear relationship with $R_{w} R_{t}^{*-1}$ with a constant of proportionality of $F^{*}$. The plot of $S w^{n *}$ against $R_{w} R_{t}^{*-1}$ should yield a straight line with slope equals to $F^{*}$. Figures 6 and 7 portray the straight lines for $S w_{n}{ }^{*}$ plotted against $R_{w} R_{t}{ }^{*-1}$; signifying the linear correlation between the two parameters. Thus, 


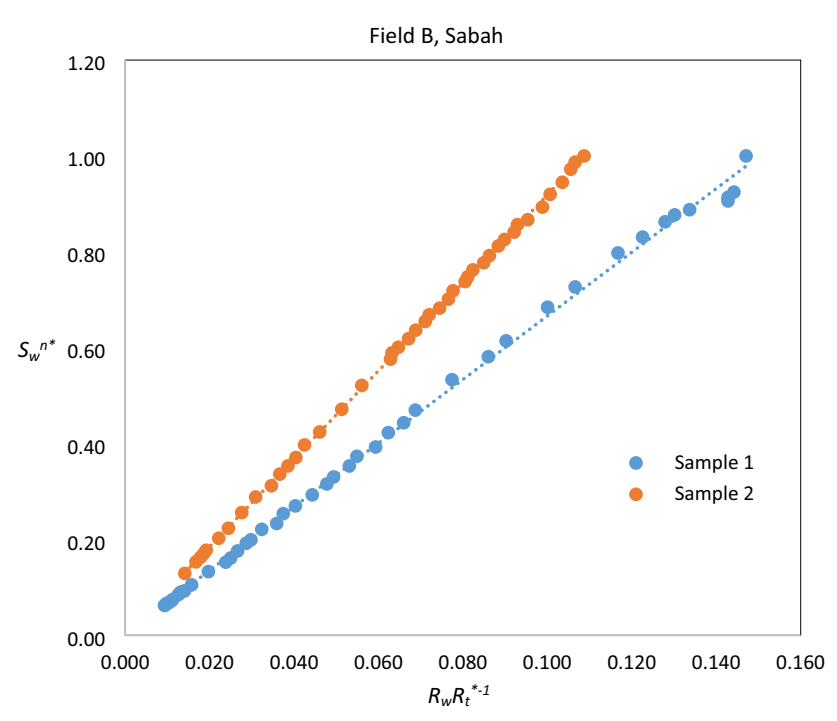

Fig. $7 S w^{n *}$ plotted against $R_{w} R_{t}^{*-1}$ for Samples 1 and 2 of Field B (straight line denotes linear relationship)

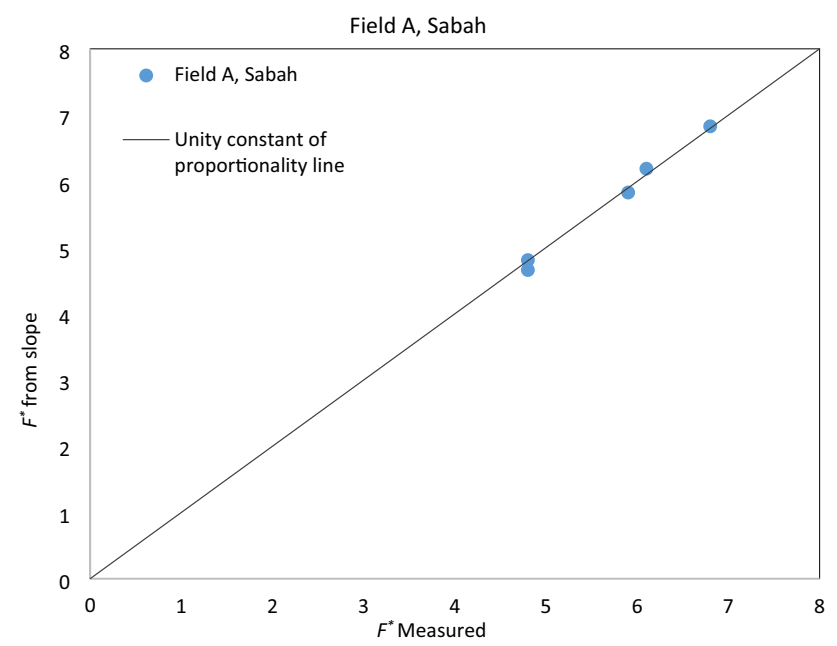

Fig. $8 F^{*}$ from slope plotted against measured $F^{*}$ for all samples from Field A (all data fell on the unity constant of proportionality line)

$F^{*}$ of each sample was determined from the slope of the graph and plotted against laboratory-measured $F^{*}$ from the formation factor analysis. Next, Figs. 8 and 9 display that all data points from both fields fell on the unity constant of proportionality line. This proves that $F^{*}$ measured in $R I-S_{w}$ analysis is similar to the measured $F^{*}$ in formation factor analysis. Hence, the assigned $F^{*}$ in Eq. 14 is indeed a valid assumption.

In the conventional method, it is common to deploy Waxman-Smits equations for both $m^{*}$ and $S_{w}$. The comparison of calculated $S_{w}$ values between variable $m *$ method and conventional method for Field A is presented in Figs. 10,

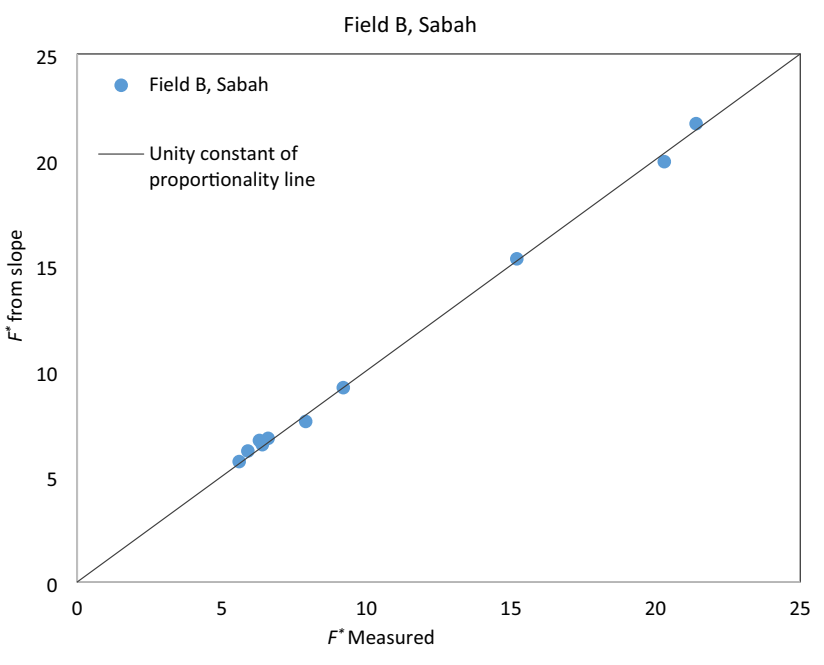

Fig. $9 F^{*}$ from slope plotted against measured $F^{*}$ for all samples from Field B (all data fell on the unity constant of proportionality line)

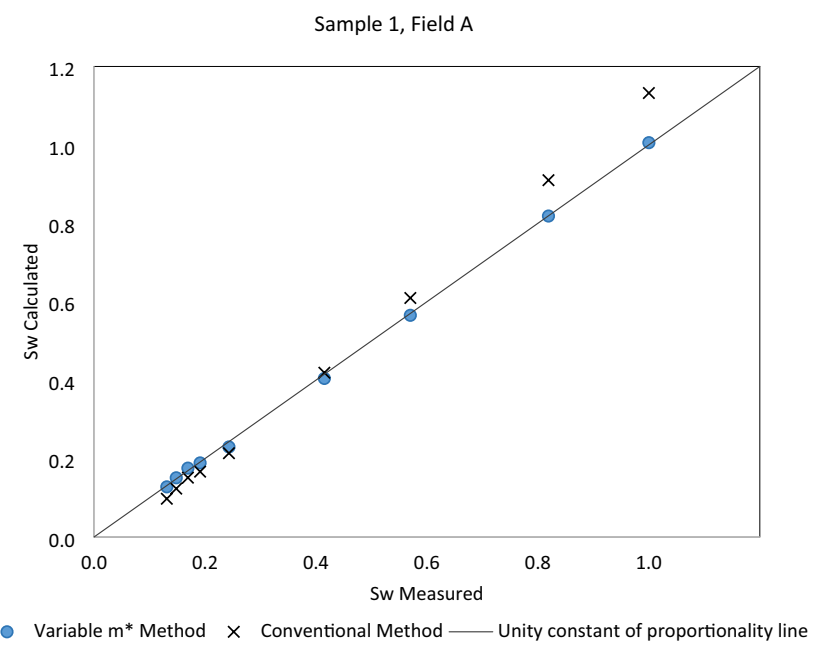

Fig. 10 The calculated $S_{w}$ versus laboratory-measured $S_{w}$ for the proposed and conventional methods of Sample 1 in Field A (data for the proposed method fell on the unity constant of proportionality line)

$11,12,13,14$, and 15. All plots show that the variable $m^{*}$ method yielded better $S_{w}$ estimation, in comparison with the conventional method.

Data calculated using variable $m *$ method fell on the unity constant of proportionality line, which indicated that the calculated $S_{w}$ matched the measured $S_{w}$. This is supported by low MAAPE at 0.02 for the proposed method (see Table 3). The conventional method gave good prediction of $S_{w}$ at lower saturation, but resulted in overestimation at higher saturation with the last data point scoring above 1.0 $S_{w}$ estimation.

The $S_{w}$ prediction for Sample 2 revealed similar trend with prediction on Sample 1. The proposed method yielded 


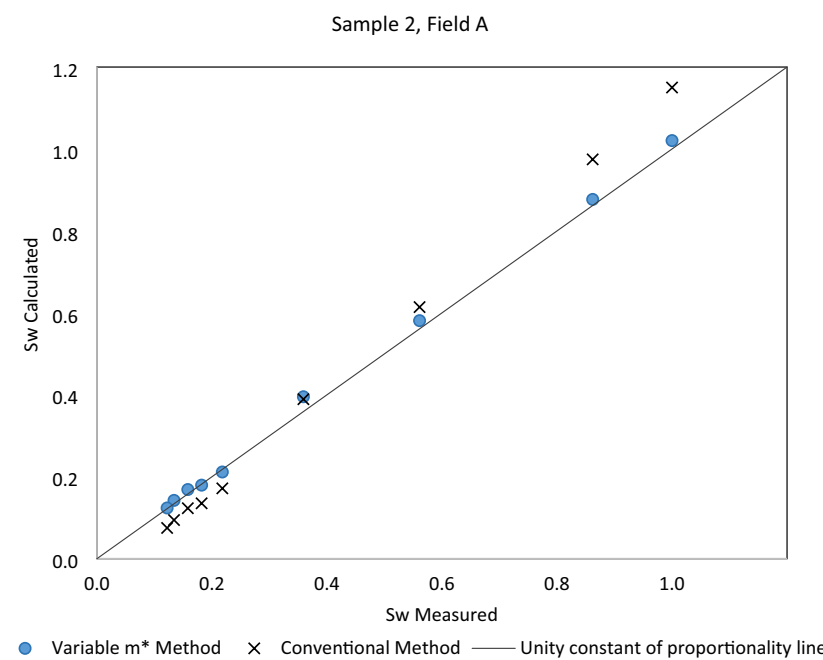

Fig. 11 The calculated $S_{w}$ versus laboratory-measured $S_{w}$ for the proposed and conventional methods of Sample 2 in Field A (data of the proposed method fell on the unity constant of proportionality line)

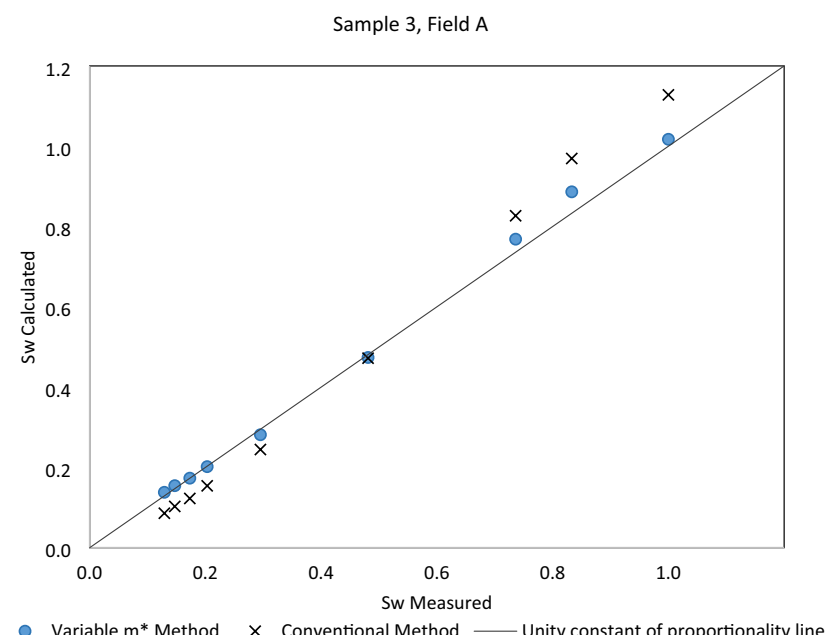

Fig. 12 The calculated $S_{w}$ versus laboratory-measured $S_{w}$ for the proposed and conventional methods of Sample 3 in Field A (data of the proposed method fell on the unity constant of proportionality line, while the conventional method overestimated at high saturation)

accurate estimation of $S_{w}$, whereas the conventional method overestimated $S_{w}$ at high saturation. The MAAPE value for the proposed method was 0.04 , while 0.20 for the conventional method. This observed trend is ascribed to the fixing of cementation factor $m$ in Waxman-Smits equation, while constantly kept the $S_{w}$ high. A similar pattern is noted for Sample 3 in Fig. 12.

For Samples 4 and 5 displayed in Figs. 13 and 14, respectively, the proposed method continued providing good approximation although $S_{w}$ was slightly underestimated, especially at high saturation region. The conventional

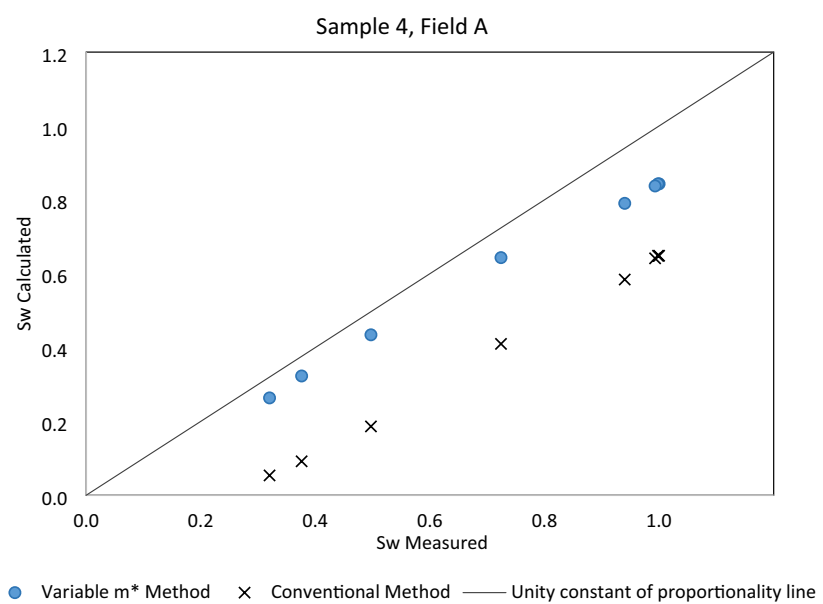

Fig. 13 The calculated $S_{w}$ versus laboratory-measured $S_{w}$ for the proposed and conventional methods of Sample 4 in Field A (prediction for both methods fell below the unity line)

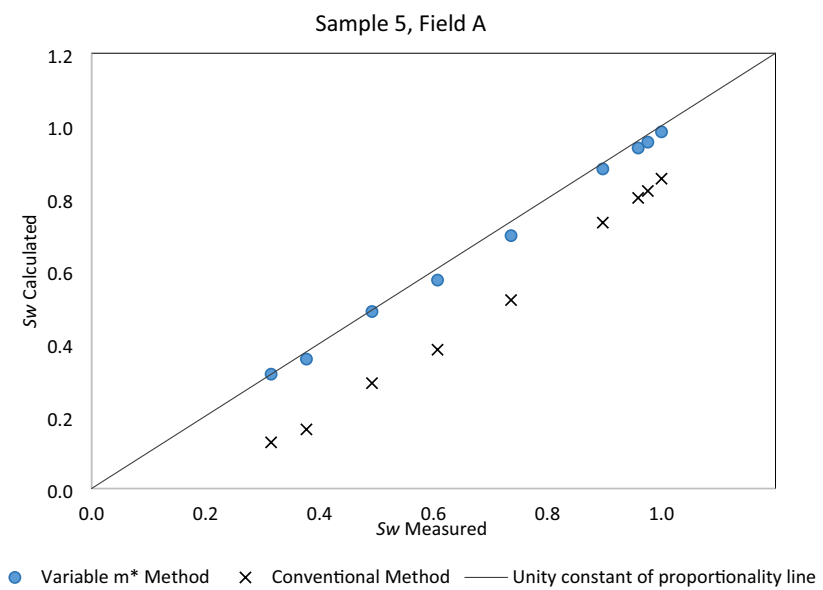

Fig. 14 The calculated $S_{w}$ versus laboratory-measured $S_{w}$ for the proposed and conventional methods of Sample 5 in Field A (the proposed method gave good prediction, while the conventional method underestimated $S_{w}$ )

method, on the other hand, yielded massive errors with MAAPE values of 0.46 and 0.30 , respectively, for Samples 4 and 5. The MAAPE values for the proposed method were 0.15 and 0.03, respectively. The huge error found for Sample 4 is attributable to the underestimation of $F^{*}$, as tabulated in Table 3.

The proportionality and MAAPE analysis of both methods for each sample are listed in Table 3. The conventional method had overestimated $S_{w}$, thus contributing to massive errors. The MAAPE for the proposed method was low; signifying the feasibility of the method in estimating $S_{w}$.

Similar to the data extracted from Field A, the proposed method displayed better match between calculated and measured $S_{w}$ in all Field B core samples. The conventional method 


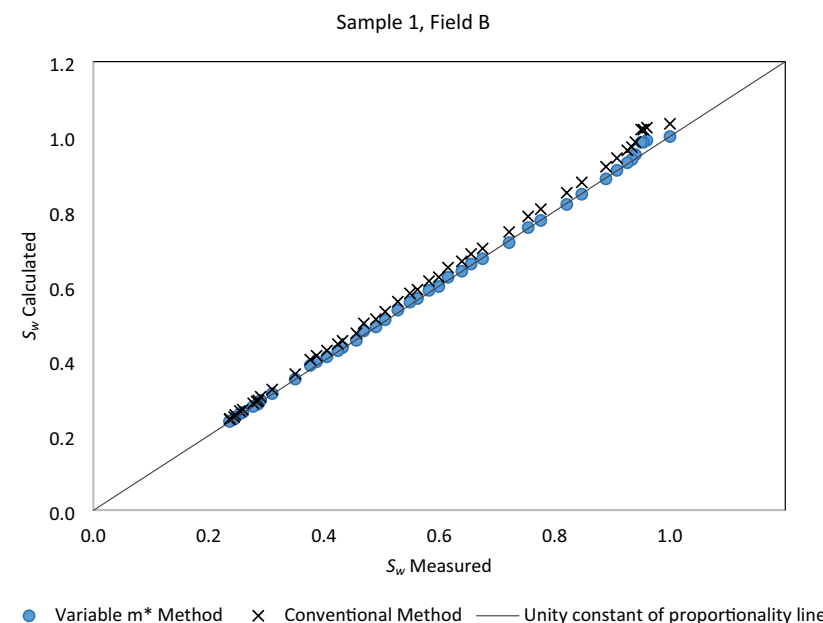

Fig. 15 The calculated $S_{w}$ versus laboratory-measured $S_{w}$ for the proposed and conventional methods of Sample 1 in Field B (data points from both methods fell on the unity constant of proportionality line)

Table 3 MAAPE analysis for both methods for Field A

\begin{tabular}{lll}
\hline Sample number & MAAPE \\
\cline { 2 - 3 } & Variable $m^{*}$ method & $\begin{array}{l}\text { Conven- } \\
\text { tional } \\
\text { method }\end{array}$ \\
\hline Sample 1 & 0.02 & 0.12 \\
Sample 2 & 0.04 & 0.20 \\
Sample 3 & 0.04 & 0.19 \\
Sample 4 & 0.15 & 0.46 \\
Sample 5 & 0.03 & 0.30 \\
\hline
\end{tabular}

via Waxman-Smits equation gave good estimation of $S_{w}$ in some samples (e.g. Sample 1 of Field B in Fig. 15) and either underestimation or overestimation in others (see Figs. 16 and 17).

Figures 16 and 17 illustrate that the conventional method either underestimated or overestimated $S_{w}$, especially in the high saturation region. This scenario is ascribed to the fixing of cementation factor $m$ in the Waxman-Smits model. The Waxman-Smits model predicted stronger $Q_{v}$ effect on low water saturation that contributed to more accurate prediction for region with low saturation. The error analysis for all samples in Field B is summarised in Table 4. The outcomes depict that the application of Eqs. 4 and 14 in the variable $m *$ method offers better $S_{w}$ estimates with lower MAAPE values.

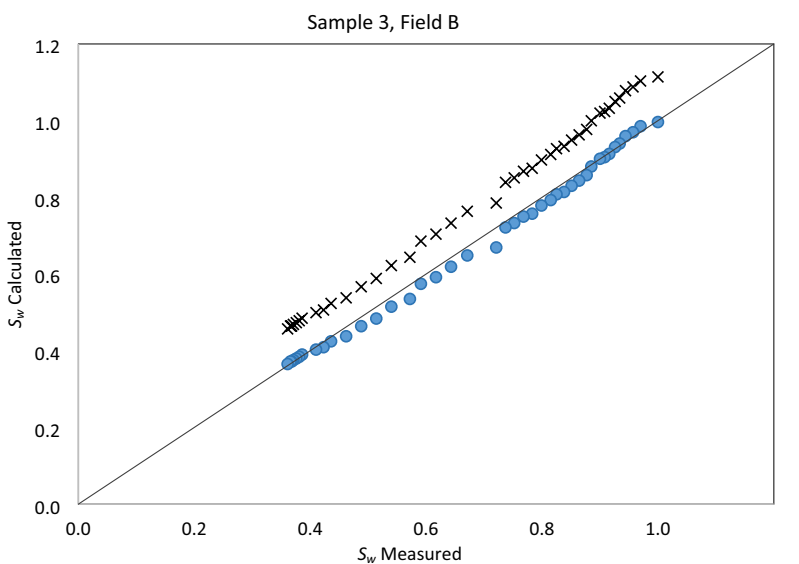

- Variable $\mathrm{m}^{*}$ Method $\times$ Conventional Method __ Unity constant of proportionality line

Fig. 16 The calculated $S_{w}$ versus laboratory-measured $S_{w}$ for the proposed and conventional methods of Sample 3 in Field B (good estimation by the proposed method, while overestimation of $S_{w}$ by the conventional method)

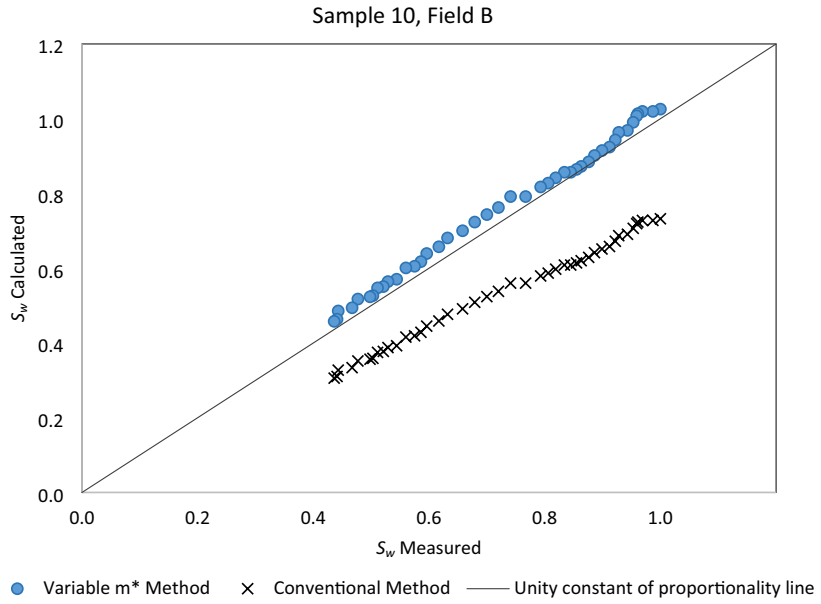

Fig. 17 The calculated $S_{w}$ versus laboratory-measured $S_{w}$ for the proposed and conventional methods of Sample 10 in Field B (good estimation by the proposed method, while underestimation of $S_{w}$ by the conventional method)

\section{Conclusion}

The variable cementation factor method yielded good estimation to the laboratory-measured values. This denotes the significance of accurately estimating formation factor in $S_{w}$ prediction. Referring to Eq. 4, instead of averaging the cementation factor to a single value to represent a particular reservoir, the cementation factor is varied with lithology type in the aspect of clay content and types, as well as geometric factor. This enables the formation factor to vary with both clay and porosity effects. In shaly part, $S_{w}$ accounts for clay conductivity. In less shaly zone, the 
Table 4 MAAPE analysis for both methods for Field B

\begin{tabular}{lll}
\hline Sample number & MAAPE \\
\cline { 2 - 3 } & Variable $m^{*}$ method & $\begin{array}{l}\text { Conven- } \\
\text { tional } \\
\text { method }\end{array}$ \\
\hline Sample 1 & 0.01 & 0.04 \\
Sample 2 & 0.13 & 0.10 \\
Sample 3 & 0.02 & 0.16 \\
Sample 4 & 0.02 & 0.10 \\
Sample 5 & 0.01 & 0.08 \\
Sample 6 & 0.09 & 0.21 \\
Sample 7 & 0.03 & 0.11 \\
Sample 8 & 0.02 & 0.13 \\
Sample 9 & 0.01 & 0.30 \\
Sample 10 & 0.05 & 0.26 \\
\hline
\end{tabular}

value was close to that predicted by Archie's equation as $B Q_{v}$ approached zero. This outcome shows that water saturation estimation can be improved at anywhere, especially in a complex heterogeneous reservoir. The analysis of data extracted from the two fields located in Sabah yielded MAAPE values that ranged at $0.01-0.15$ and $0.04-0.46$ for variable cementation factor and conventional method, respectively.

Acknowledgements This study is funded by Fundamental Research Grant Scheme (FRGS/1/2019/TK07/UITM/03/1). The author also acknowledges the sponsorship of a programme provided by the Ministry of Higher Education (MOHE), Malaysia (SLAI Fellowship Scheme), together with Universiti Teknologi MARA (UiTM), Malaysia.

Funding This study is funded by the Fundamental Research Grant Scheme (FRGS/1/2019/TK07/UITM/03/1) by the Ministry of Higher Education, Malaysia.

\section{Declarations}

Conflict of interest On behalf of the authors, the corresponding author would like to state that neither known competing financial interest nor personal relationships have influenced the work reported in this paper.

Open Access This article is licensed under a Creative Commons Attribution 4.0 International License, which permits use, sharing, adaptation, distribution and reproduction in any medium or format, as long as you give appropriate credit to the original author(s) and the source, provide a link to the Creative Commons licence, and indicate if changes were made. The images or other third party material in this article are included in the article's Creative Commons licence, unless indicated otherwise in a credit line to the material. If material is not included in the article's Creative Commons licence and your intended use is not permitted by statutory regulation or exceeds the permitted use, you will need to obtain permission directly from the copyright holder. To view a copy of this licence, visit http://creativecommons.org/licenses/by/4.0/.

\section{References}

Aguilera R (1976) Analysis of naturally fractured reservoirs from conventional well logs. J Pet Technol 28:764-772

Archie GE (1942) The electrical resistivity log as an aid in determining some reservoir characteristics. Trans Am Inst Min Metallur Eng 146:54-62

Atkins ER Jr, Smith GH (1961) The significance of particle shape in formation resistivity factor-porosity relationships. J Petrol Technol 13(03):285-291

Bakar WZW et al (2019) Derivation of formation factor in shaly sandstone with geometry and clay conductivity effects. J Pet Sci Eng 182:106359

Cai J, Zhang Z, Wei W, Guo D, Li S, Zhao P (2019) The critical factors for permeability-formation factor relation in reservoir rocks: pore-throat ratio, tortuosity and connectivity. Energy 188:116051

Clavier C, Coates G, Dumanoir J (1984) Theoretical and experimental bases for the dual-water model for interpretation of shaly sands. Soc Petrol Eng J 24(02):153-168

Ehrlich R, Etris EL, Brumfield D, Yuan LP, Crabtree SJ (1991) Petrography and reservoir physics III-Physical models for permeability and formation factor. Bull Am Assoc Pet Geol 75:1579-1592

Ghanbarian B, Hunt AG, Ewing RP, Skinner TE (2014) Universal scaling of the formation factor in porous media derived by combining percolation and effective medium theories. Geophys Res Lett 41(11):3884-3890

Glover PWJ (2009) What is the cementation exponent? A new interpretation. Lead Edge 28(1):82-85

Herrick DC, Kennedy WD (2009) A new look at electrical conduction in porous media: a physical description of rock conductivity. SPWLA 50th annual logging symposium. Society of Petrophysicists and Well-Log Analysts

Jakosky JJ, Hopper RH (1937) The effect of moisture on the direct current resistivities of oil sands androcks. Geophysics 2(1):33-54

Kim S, Kim H (2016) A new metric of absolute percentage error for intermittent demand forecasts. Int J Forecast 32(3):669-679

Leverett MoC (1941) Capillary behavior in porous solids. Transactions of the AIME 142(1):152-169

Martin M, Murray GH, Gillingham WJ (1938) Determination of the potentialproductivity of oil-bearing formations by resistivity measurements. Geophysics 3(3):258-272

Mungan N, Moore EJ (1968) Certain wettability effects on electrical resistivity in porous media. J Can Pet Technol 7(01):20-25

Owen JE (1952) The resistivity of a fluid-filled porous body. J Petrol Technol 4(07):169-174

Patnode HW, Wyllie MRJ (1952) The presence of conductive solids in reservoir rocks as a factor in electric log interpretation. J Petrol Technol 2:47-52

Perez-Rosales C (1982) On the relationship between formation resistivity factor and porosity. Soc Petrol Eng J 22(04):531-536

Salem HS, Chilingarian GV (1999) The cementation factor of Archie's equation for shaly sandstone reservoirs. J Petrol Sci Eng 23(2):83-93

Sauer MC, Southwick PF, Spiegler KS, Wyllie MRJ (1955) Electrical conductance of porous plugs-ion exchange resin-solution systems. Ind Eng Chem 47(10):2187-2193

Waxman MH, Smits LJM (1968) Electrical conductivities in oil-bearing shaly sands. Soc Petrol Eng J 8(02):107-122

Winsauer WO, McCardell WM (1953) Ionic double-layer conductivity in reservoir rock. J Petrol Technol 5(05):129-134

Winsauer WO, Shearin HM Jr, Masson PH, Williams M (1952) Resistivity of brine-saturated sands in relation to pore geometry. Am Asso Petrol Geol Bull 36(2):253-277

Worthington PF (1985) The evolution of shaly-sand concepts in reservoir evaluation. Log Anal 26:01 
Wyllie MRJ, Gregory AR (2012) Formation factors of unconsolidated porous media: influence of particle shape and effect of cementation. J Petrol Technol 5:103-110

Wyllie MRJ, Southwick PF (1954) An experimental investigation of the SP and resistivity phenomena in dirty sands. J Petrol Technol 6(02):44-57

Wyckoff RD, Botset HG (1936) The flow of gas-liquid mixtures through unconsolidatedsands. Physics 7(9):325-345
Publisher's Note Springer Nature remains neutral with regard to jurisdictional claims in published maps and institutional affiliations. 